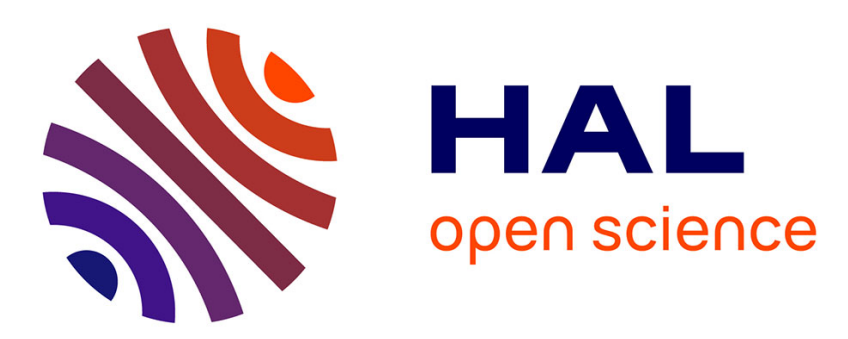

\title{
Predictions of tensile strength of binary tablets using linear and power law mixing rules
}

\author{
Abderrahim Michrafy, Mohammed Michrafy, Moulay S. Kadiri, John A. \\ Dodds
}

\section{> To cite this version:}

Abderrahim Michrafy, Mohammed Michrafy, Moulay S. Kadiri, John A. Dodds. Predictions of tensile strength of binary tablets using linear and power law mixing rules. International Journal of Pharmaceutics, 2007, 333 (1-2), pp.118-126. 10.1016/j.ijpharm.2006.10.008 . hal-01680765

\section{HAL Id: hal-01680765 \\ https://hal.science/hal-01680765}

Submitted on 6 Sep 2018

HAL is a multi-disciplinary open access archive for the deposit and dissemination of scientific research documents, whether they are published or not. The documents may come from teaching and research institutions in France or abroad, or from public or private research centers.
L'archive ouverte pluridisciplinaire HAL, est destinée au dépôt et à la diffusion de documents scientifiques de niveau recherche, publiés ou non, émanant des établissements d'enseignement et de recherche français ou étrangers, des laboratoires publics ou privés. 


\title{
Predictions of tensile strength of binary tablets using linear and power law mixing rules
}

\author{
A. Michrafy ${ }^{a}, *$, M. Michrafy ${ }^{b}$, M.S. Kadiri ${ }^{a}$, J.A. Dodds ${ }^{a}$ \\ ${ }^{a}$ Chemical Engineering Laboratory for Particulate Solids, UMR CNRS 2392, Ecole des Mines d'Albi-Carmaux, \\ Campus Jarlard, Albi, France \\ ${ }^{\mathrm{b}}$ Department of Management and Methods, ESC Group, Bordeaux, France
}

\begin{abstract}
There has recently been an increased interest in predicting the tensile strength of binary tablets from the properties of the individual components. In this paper, measurements are reported for tensile strength of tablets compressed from single-component and binary powder mixtures of lactose with microcrystalline cellulose (MCC), and lactose with two types of silicified microcrystalline cellulose (SMCC and SMCC-HD), which are different in compressibility. Measurements show the tensile strength increases with the relative density for single powders, and both with the relative density and the mass fraction of cellulose in the mixtures. It was also observed, for binary mixtures compacted at 50 and $150 \mathrm{MPa}$, that there was a slight variation in porosity with the mass fraction of celluloses.

The predictions of the tensile strength of binary tablets from the characteristics of the single-components was analysed with the extended Ryshkewitch-Duckworth model by assuming both linear and power law mixing rules for the determination of the parameters "tensile strength at zero porosity and bonding capacity constant". As consequence, four models were analysed and compared with measurements using criteria based on the standard deviation from the mean values. Results showed a good prediction using a linear mixing rule combined with the power law. However, as the predictions of these models depend on the powders and the porosity range for the characterization of single-components, none of them can be systematically considered as being the best to predict binary behaviour from data for individual powders.
\end{abstract}

Keywords: Compaction; Tensile strength; Binary mixtures; Tablets; Mixing rules

\section{Introduction}

Studies of tablet formation by direct compression are often based on a single free powder, a granulated powder or a powder with an addition of a small percentage of binder. As the majority of formulated pharmaceutical tablets consist of mixtures of more than one powder, an important problem is to predict the properties of tablets obtained by compression of powder mixtures from the properties of the individual components. In most published work, tensile strength of tablets is implicitly assumed to be a reflection of the bonding contact between particles following the compaction. However, factors such as particle size, particle shape, porosity distribution may also be involved. In

\footnotetext{
* Corresponding author at: LGPSD UMR 2392, Ecole des Mines d' AlbiCarmaux, 81000 Albi, France. Tel.: +33 5634931 62; fax: +33563493025.

E-mail address: michrafy@enstimac.fr (A. Michrafy).
}

binary tablets, several studies have been carried out on the correlation between tensile strength and composition of the two components, particularly in binary mixtures where one of powders is ductile and the other is fragmentary (Sheikh-Salem and Fell, 1981; Leuenberger, 1985; Vromans et al., 1988; Riepma et al., 1990; Kuentz et al., 2000; Hutin et al., 2003; Ramirez et al., 2004; Van Veen et al., 2004; Wu et al., 2005). Two main methods are used in such studies. The first involves the characterization of compaction properties of mixtures and the influence of mixture composition on pressure-density relationships. The second is oriented toward predictions of the properties of binary tablets from the properties of the individual components (Chan et al., 1983; Kuentz and Leuenberger, 2000; Ramirez et al., 2004; Wu et al., 2005; Busignies et al., 2006a,b). Literature results for the compaction of binary mixtures show the complexity of the phenomena involved and the problems inherent in defining a single theory to explain the tensile strength of binary tablet from the behaviour of individual components. The work of Sheikh- 
Salem and Fell (1981) showed that the addition of small quantity of lactose to sodium chloride considerably reduces the tensile strength. The study of Vromans and Lerk (1988) showed that the addition of small quantities of roller-dried $\beta$-lactose to cellulose does not produce a significant decrease of tensile strength even if cellulose and sodium chloride seem to have similar mechanical behaviour in compaction. The physicochemical properties (adhesive or cohesive forces) may play a significant role in bonding particles and could explain the results mentioned above. In particular Sheikh-Salem and Fell (1981) assumed that lactose and sodium chloride have no bonding affinity. In addition to these complexities, factors such as powder flowability and compressibility are also pertinent parameters that could induce effects on values of the tensile strength of tablets formed from mixed powders. Indeed, good flowability would favour the homogeneity of the mixing, whereas the good compressibility gives the possibility of increasing tensile strength at low pressures. This latter behaviour is important for selecting the appropriate excipient for mixing with powders such as nutraceutical and functional foods where the compaction load has to be moderate at the same time as the tablet must have a sufficient resistance for handling.

The objective of this study is first to experimentally determine tensile strength of tablets compressed from binary mixtures of lactose and one of three different microcrystalline celluloses. Then the prediction of tensile strength of binary tablets from individual properties of the components is analysed by assuming both linear and power law mixing rules for calculating the parameters of the modified Ryshewitch-Duckworth model. Predictions of the different proposed combinations are compared with the experimental data by a statistical criterion and the possibility of finding better combinations is discussed.

\section{Materials and methods}

\subsection{Materials}

Excipients differing in mechanical properties such as flowability, compressibility or compactability are often used to optimize the user properties of tablets and confer functionalities to a formulation. Excipients containing microcrystalline cellulose have been developed by JRS Pharma to give powders such as Prosolv ${ }^{\circledR} 90$ and Prosolv ${ }^{\circledR} 90$ HD for pharmacy and foods formulation. Compared with microcrystalline cellulose Vivapur ${ }^{\circledR}$ 102 (MCC), these silicified microcrystalline cellulose excipients (noted SMCC) contain $98 \%$ of MCC and $2 \%$ of colloidal silicon dioxide co-processed to give intimate mixtures (Sherwood and
Becker, 1998). They present a rougher surface, a better flowability and compressibility, this is particularly the case for Prosolv ${ }^{\circledR}$ HD 90 (noted SMCC-HD). The basic characteristics of these powders (particle size, bulk density and true density) were presented in Table 1.

To analyse properties of tablets compacted from binary mixtures, MCC, SMCC and SMCC-HD excipients were added to the lactose Granulac ${ }^{\circledR} 140$ (Meggle Gmbh) in different compositions. Scanning electron microscopy images of these excipients are shown in Fig. 1.

\subsection{Preparation of the binary mixtures}

The lactose powder was blended with MCC (respectively, SMCC and SMCC-HD) in various mass fractions in $100 \mathrm{~g}$ lots that were thoroughly mixed in a Turbula mixer (from Turbula ${ }^{\circledR}$, System Schatz, Basel Switzerland) for $15 \mathrm{~min}$ at $32 \mathrm{rpm}$. The true density of single-components and binary mixtures was measured using a Micrometrics AccuPyc 1330 helium gas displacement pycnometer. Results of the true densities of powders and mixtures are reported in Table 1 for single powders and in Table 2 for mixtures.

\subsection{Tablets preparation}

Cylindrical flat tablets have been made from these powders by the following procedure. A mass of $0.4 \pm 0.003 \mathrm{~g}$ of powder (respectively, single-components or binary mixtures of powders) was manually poured into a cylindrical die $11.28 \mathrm{~mm}$ in diameter (die section $1-\mathrm{cm}^{2}$ ) and compacted at different pressures using an Instron universal testing machine with a $30 \mathrm{kN}$ load cell. The compaction was made at the speed of $10 \mathrm{~mm} / \mathrm{min}$ at the ambient temperature of $25 \pm 1{ }^{\circ} \mathrm{C}$. Once the tablet was ejected, its mass was measured with an electronic balance (CP 224S, Sartorius, Germany) and its dimensions (diameter and thickness) were measured with digital micrometer (Mitutoyo). The apparent and relative densities were recorded. The diametrical crushing load was then measured with the Erweka TBH 30 apparatus (from Erweka $^{\circledR}$ Gmbh Heussenstamm, Germany). For each pressure level, three compacts were made using this procedure and each measurement presented in this study is the mean of the characteristics of three tablets.

\subsection{Characterization of tablets}

The relative density of a tablet is defined as the ratio of the apparent density $\rho_{\mathrm{a}}$ of tablet to the true density $\rho_{\mathrm{t}}$ of powder. It

Table 1

Basic characteristics and fitted material parameters of Ryshkewitch-Duckworth model from "porosity-tensile strength" curve of powders: lactose (Granulac ${ }^{\circledR} 140$ from Meggle Gmbh), MCC (Vivapur ${ }^{\circledR}$ 102), SMCC (Prosolv ${ }^{\circledR}$ 90) and SMCC-HD (Prosolv ${ }^{\circledR} 90$ HD) from J. Rettenmaier \& Söhn

\begin{tabular}{|c|c|c|c|c|c|}
\hline Materials & $\begin{array}{l}\text { Average particle } \\
\text { size }(\mu \mathrm{m})\end{array}$ & Bulk density $\left(\mathrm{g} / \mathrm{cm}^{3}\right)$ & True density $\left(\mathrm{g} / \mathrm{cm}^{3}\right)$ & Bonding constant & $\begin{array}{l}\text { Tensile strength at } \\
\text { zero porosity }(\mathrm{MPa})\end{array}$ \\
\hline SMCC & 90 & 0.32 & $1.5981 \pm 0.003$ & 7.72 & 37.14 \\
\hline SMCC-HD & 90 & 0.32 & $1.5898 \pm 0.001$ & 7.14 & 24.19 \\
\hline $\mathrm{MCC}$ & 90 & 0.32 & $1.599 \pm 0.0012$ & 5.95 & 21.11 \\
\hline Lactose & 70 & 0.66 & $1.5617 \pm 0.0022$ & 20.15 & 12.89 \\
\hline
\end{tabular}




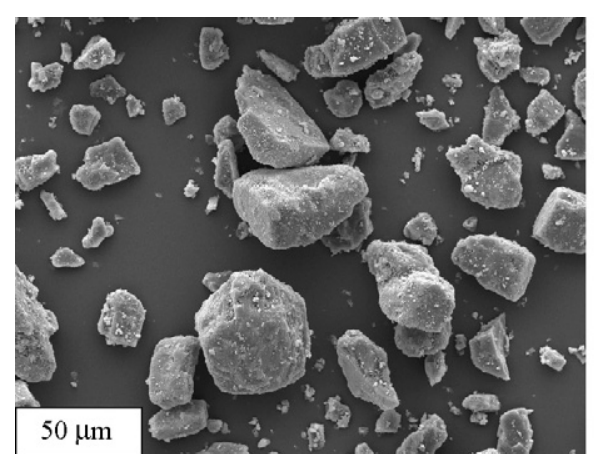

(a) lactose (Granulacß) 140)

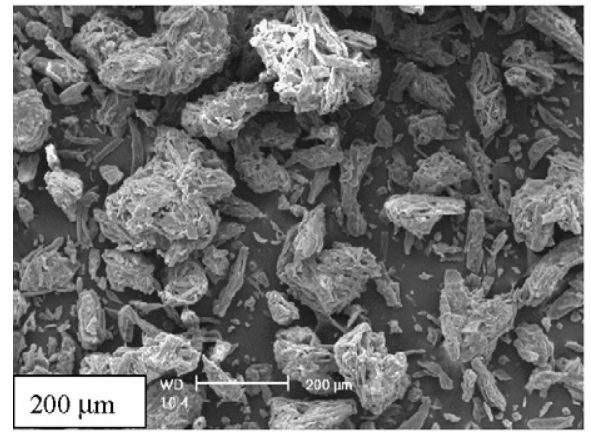

(c) SMCC (Prosolv(俍 90)

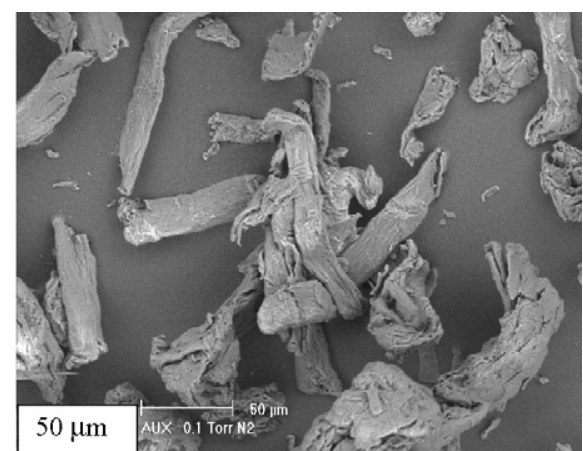

(b) MCC (Vivapur $\mathbb{R}$ 102)

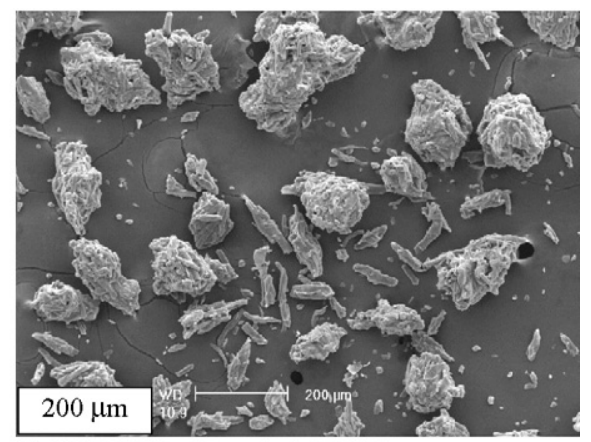

(d) SMCC-HD (Prosolv() 90 HD)

Fig. 1. Scanning electron microscopy images of powders lactose (Granulac ${ }^{\circledR}$ 140) (a), MCC (Vivapur ${ }^{\circledR}$ 102) (b), SMCC (Prosolv $\left.{ }^{\circledR} 90\right)(\mathrm{c})$ and SMCC-HD (Prosolv ${ }^{\circledR}$ $90 \mathrm{HD})(\mathrm{d})$.

is equal to 1 minus the porosity. For each composition, the true density of powders was measured with a helium pycnometer and the apparent density was calculated from the powder mass and the tablet dimensions (diameter and thickness) as:

$\rho_{\mathrm{a}}=\frac{m}{\pi h D^{2} / 4}$

where $m$ is the mass of the tablet, and $h$ and $D$ its thickness and diameter.

The tensile strength $\left(\sigma_{\mathrm{t}}\right)$ of tablet is calculated as follows (Fell and Newton, 1970):

$\sigma_{\mathrm{t}}=\frac{2 F}{\pi D h}$

where $F$ is the load required to break the tablet diametrically.

\subsection{Approaches to predict tensile strength of binary mixtures tablets}

In the literature, two approaches have been investigated for predicting the tensile strength $\sigma_{\mathrm{t}, \mathrm{m}}$ of binary tablets from the relative density $\rho_{\mathrm{r}, \mathrm{m}}$ (or the porosity $\varepsilon=1-\rho_{\mathrm{r}, \mathrm{m}}$ ) of the mixture. One is based on Percolation theory (Leuenberger, 1985; Kuentz and Leuenberger, 2000; Ramirez et al., 2004) and the second on the Ryshkewitch-Duckworth model (Ryshkewitch, 1953; Duckworth, 1953; Wu et al., 2005).

Percolation theory applied to the tensile strength of binary mixtures results in a power law expression involving the relative density and a critical value corresponding to the percolation threshold $\rho_{\mathrm{c}, \mathrm{m}}$ (minimum solid fraction needed to build a network of relevant contact points). It is assumed that one component dominates the overall strength of the tablet. For tablets with a relative density $\rho_{\mathrm{r}, \mathrm{m}}>\rho_{\mathrm{c}, \mathrm{m}}$, the tensile strength $\sigma_{\mathrm{t}, \mathrm{m}}$ is given as:

$\sigma_{\mathrm{t}, \mathrm{m}}=k_{\mathrm{m}}\left(\rho_{\mathrm{r}, \mathrm{m}}-\rho_{\mathrm{c}, \mathrm{m}}\right)^{2.7}$

where $k_{\mathrm{m}}$ is a material constant and the 2.7 is a universal constant related to the structure of the particle contact network. The critical relative density of the mixtures $\rho_{\mathrm{c}, \mathrm{m}}$ is related to those of the components $\rho_{\mathrm{c}, 1}$ and $\rho_{\mathrm{c}, 2}$ as:

$\rho_{\mathrm{c}, \mathrm{m}}=\alpha \rho_{\mathrm{c}, 1}+(1-\alpha) \rho_{\mathrm{c}, 2}$

Table 2

Measured and predicted true densities (Eq. (8)) of binary mixtures "SMCC/lactose", "SMCC-HD/lactose" and "MCC/lactose"

\begin{tabular}{|c|c|c|c|c|c|c|}
\hline \multirow[t]{2}{*}{ Fraction mass of lactose } & \multicolumn{3}{|c|}{ Measured true density $\left(\mathrm{g} / \mathrm{cm}^{3}\right)$} & \multicolumn{3}{|c|}{ Predicted true density $\left(\mathrm{g} / \mathrm{cm}^{3}\right)$} \\
\hline & SMCC & SMCC-HD & $\mathrm{MCC}$ & SMCC & SMCC-HD & MCC \\
\hline 0.75 & $1.5664 \pm 0.0005$ & $1.5692 \pm 0.0008$ & $1.5524 \pm 0.0016$ & 1.5706 & 1.5686 & 1.5709 \\
\hline 0.5 & $1.5813 \pm 0.0015$ & $1.5754 \pm 0.001$ & $1.5564 \pm 0.0014$ & 1.5797 & 1.5756 & 1.5801 \\
\hline 0.25 & $1.5861 \pm 0.0012$ & $1.5883 \pm 0.001$ & $1.5617 \pm 0.0019$ & 1.5888 & 1.5827 & 1.5895 \\
\hline
\end{tabular}




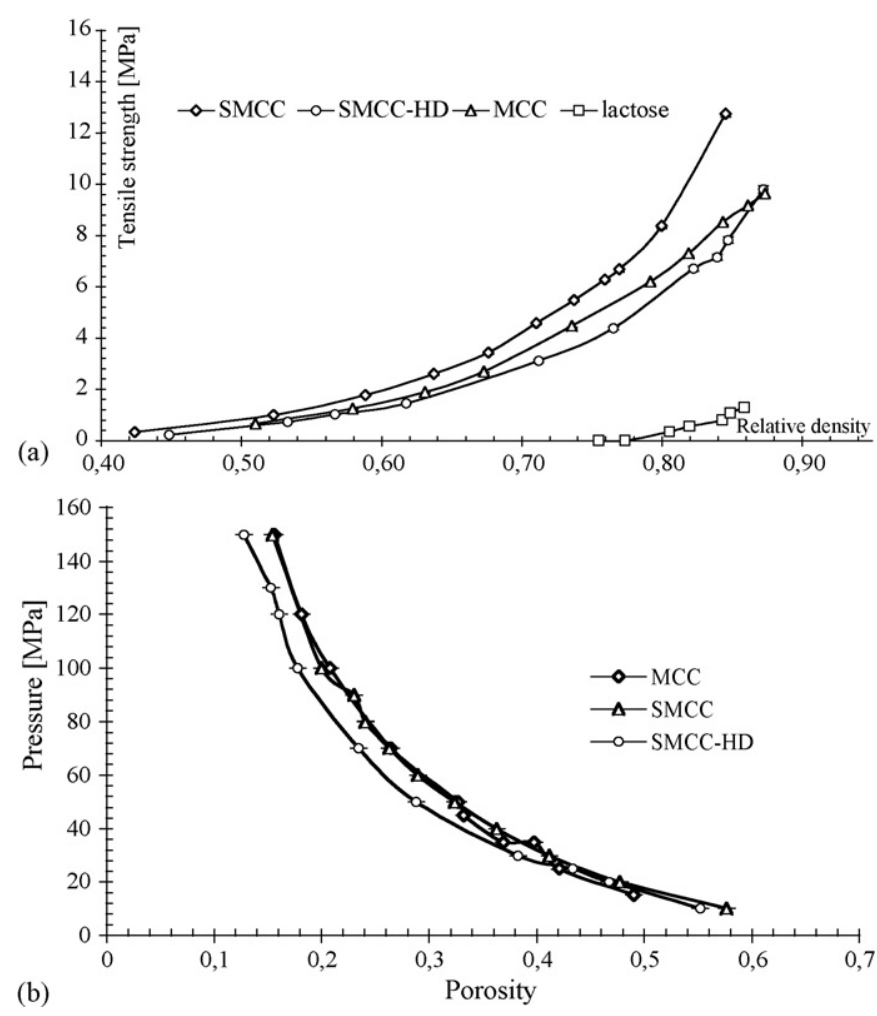

Fig. 2. (a) Tensile strength of tablets compacted from powder of lactose, MCC, SMCC, SMCC-HD (tablets prepared at different pressures in a $11.28 \mathrm{~mm}$ die diameter). (b) Porosity-pressure correlations for MCC, SMCC and SMCC-HD powders.

The constant $\alpha$ is the mass fraction of the well compactable component in the binary mixtures. However, in our case it was difficult to determine the critical relative density of lactose powder. Between 50 and $70 \mathrm{MPa}$ of pressure, the tensile strength of tablets was zero. At $100 \mathrm{MPa}$ of pressure, the tensile strength was non-null. The tensile strength versus relative density curve of the lactose is plotted in Fig. 2. The change of the slope that corresponds to the percolation threshold could occur between 75 and $95 \mathrm{MPa}$. Unfortunately, in this range, no data was recorded. Our study was then oriented towards the application of the Ryshkewitch-Duckworth approach. The Ryshkewitch-Duckworth model was first applied to the tensile strength of porous sintered alumina and zirconia (Ryshkewitch, 1953) and discussed in Duckworth (1953). The model was recently adapted and applied to predict the tensile strength of binary tablets of MCC and HPMC or MCC and Starch (Wu et al., 2005). The predictive equation of tensile strength for binary tablets is as follows:

$\ln \left(\frac{\sigma_{\mathrm{t}, \mathrm{m}}}{\sigma_{\infty, \mathrm{m}}}\right)=-\kappa_{\mathrm{m}} \varepsilon_{\mathrm{m}}$

where $\sigma_{\infty, \mathrm{m}}$ is the tensile strength of binary tablet at zero porosity and $\kappa_{\mathrm{m}}$ is a material constant representing the bonding capacity of the material. These two constants depend on the composition of the powder mixture. The tensile strength of binary tablets at zero porosity $\sigma_{\infty, \mathrm{m}}$ is here assumed to be determined from those of components $\sigma_{\infty, 1}$ and $\sigma_{\infty, 2}$ using two different combination rules (i and ii): (i) The linear mixing rule which assumes that in a fully densified material the volumes of the components do not undergo notable changes:

$$
\sigma_{\infty, \mathrm{m}}=\eta \sigma_{\mathrm{m}, 1}+(1-\eta) \sigma_{\mathrm{m}, 2}
$$

(ii) A power law relation as in (Leuenberger, 1985; Kuentz and Leuenberger, 2000):

$$
\sigma_{\infty, \mathrm{m}}=\left(\sigma_{\mathrm{m}, 1}\right)^{\eta}\left(\sigma_{\mathrm{m}, 2}\right)^{1-\eta}
$$

Here $\eta$ is the volume fraction of SMCC that is related to the weight fraction $\alpha$, the true density $\rho_{\mathrm{t}, 1}$ and the true density of the binary mixtures $\rho_{\mathrm{t}, \mathrm{m}}$ as:

$\eta=\frac{\alpha \rho_{\mathrm{t}, \mathrm{m}}}{\rho_{\mathrm{t}, 1}}$

The true density $\rho_{\mathrm{t}, \mathrm{m}}$ of the binary mixtures can be expressed by linear combination as:

$\rho_{\mathrm{t}, \mathrm{m}}=\left(\frac{\alpha}{\rho_{\mathrm{t}, 1}}+\frac{1-\alpha}{\rho_{\mathrm{t}, 2}}\right)^{-1}$

It follows that predictions of tensile strength of a binary tablet can be determined from the properties of the individual components if the material constant of the binary mixtures $\kappa_{\mathrm{m}}$ can be estimated from the material constants $\kappa_{1}$ and $\kappa_{2}$ of the two components. Here also there are two possibilities: the linear mixing and the power law rules:

$\kappa_{\mathrm{m}}=\eta \kappa_{1}+(1-\eta) \kappa_{2}$

$\kappa_{\mathrm{m}}=\kappa_{1}^{\eta} \kappa_{2}^{1-\eta}$

Finally, by determining material parameters of components from experimental data such $\alpha, \rho_{\mathrm{t}, i}, \kappa_{i}$ and $\sigma_{\mathrm{m}, i}(i=1,2)$ and assuming a linear or power law mixing rule (Eqs. (6), (7), (10) and (11)), the material parameters of the binary mixtures such as true density $\rho_{\mathrm{t}, \mathrm{m}}$, tensile strength at zero porosity $\sigma_{\infty, \mathrm{m}}$ and the constant $\kappa_{\mathrm{m}}$ can be predicted. It follows from Eq. (5) and expressions of $\sigma_{\infty, \mathrm{m}}$ and $\kappa_{\mathrm{m}}$ that there are four possibilities for predicting the tensile strength of binary tablets from the relative density:

$\sigma_{\mathrm{t}, \mathrm{m}}=\sigma_{\infty, \mathrm{m}} \exp \left(-\kappa_{\mathrm{m}}\left(1-\rho_{\mathrm{r}, \mathrm{m}}\right)\right)$

where $\kappa_{\mathrm{m}}$ and $\sigma_{\infty, \mathrm{m}}$ are calculated from the following equations:

\begin{tabular}{lll}
\hline Linear-linear & (LL) & Eqs. (6) and (10) \\
Power-power & (PP) & Eqs. (7) and (11) \\
Linear-power & (LP) & Eqs. (6) and (11) \\
Power-linear & (PL) & Eqs. (7) and (10) \\
\hline
\end{tabular}

Predictions from the above models will be compared with the experimental data of the powder mixtures "lactose/MCC", "lactose/SMCC", "lactose/SMCC-HD" using a statistical criterion (mean values and standard deviation) over the range of porosity studied. 


\subsection{Criteria for comparisons}

One way to compare and discriminate between the predictions of the four models presented below (Eq. (12) and (LL), (PP), (LP) and (PL) combinations) is to calculate, for each mixture, the mean of the absolute difference between the measured $\sigma_{\mathrm{t} \text {,meas }}$ and the predicted $\sigma_{\mathrm{t} \text {,pred }}\left(\Delta \sigma=\left|\sigma_{\mathrm{t} \text {,meas }}-\sigma_{\mathrm{t} \text {,pred }}\right|\right)$ tensile strength over the studied range of porosity.

mean $=\frac{\Sigma \Delta \sigma}{N}$

and standard deviation, which measures the dispersion of values about the mean

$\operatorname{disp}=\left[\frac{N \Sigma \Delta \sigma^{2}-(\Sigma \Delta \sigma)^{2}}{N^{2}}\right]^{1 / 2}$

where $N$ is the number of data in the range of porosity and $|\cdot|$ represents the absolute value. Results of this comparison are presented in Tables $4 b, 5 b$ and $6 b$ for each mixture.

\section{Results and discussion}

\subsection{Tensile strength of tablets made from single-component powders}

Tensile strength of tablets prepared from single-component powders (lactose, MCC, SMCC and SMCC-HD) is plotted in Fig. 2a as a function of relative density. It can be seen that for all powders the tensile strength increases with the relative density. Errors of measurements of tensile strength (error bar was plotted in Fig. 2a were less than 0.15 MPa for SMCC (respectively, 0.15 for SMCC-HD, 0.15 for MCC and 0.12 for lactose). As it is shown in Fig. 2a, tensile strength of single-components is in the order "lactose $<$ SMCC-HD $<$ MCC $<$ SMCC".

The compressibility of powders MCC, SMCC, and SMCCHD (the compressibility is the ability of powder to reduce in volume under pressure) is represented by the "porosity versus pressure" curves plotted in Fig. 2b. It can be seen that SMCCHD is more compressible than MCC and SMCC. This means that, tablets of SMCC-HD need less pressure than do those made from MCC and SMCC, to reach the same porosity and hence the same tensile strength (porosity is the primary factor influencing tensile strength). As a consequence, SMCC-HD seems to be more appropriate than MCC and SMCC for the optimization of nutraceutical and enzymes formulations where the required cohesion has to be sufficient at moderate pressures.

\subsection{Properties of binary powder mixtures and tablets}

The true density of binary mixtures "MCC/lactose", "SMCC/lactose" and "SMCC-HD/lactose" were measured for the proportions $25-75,50-50$ and $75-25 \%$ in mass. Results are reported in Table 2. Predictions of the true densities of binary mixtures based on Eqs. (8) and (9) and the true densities of the single-components (Table 1), are given in Table 2. The predicted and measured true densities are in agreement. This result is con-

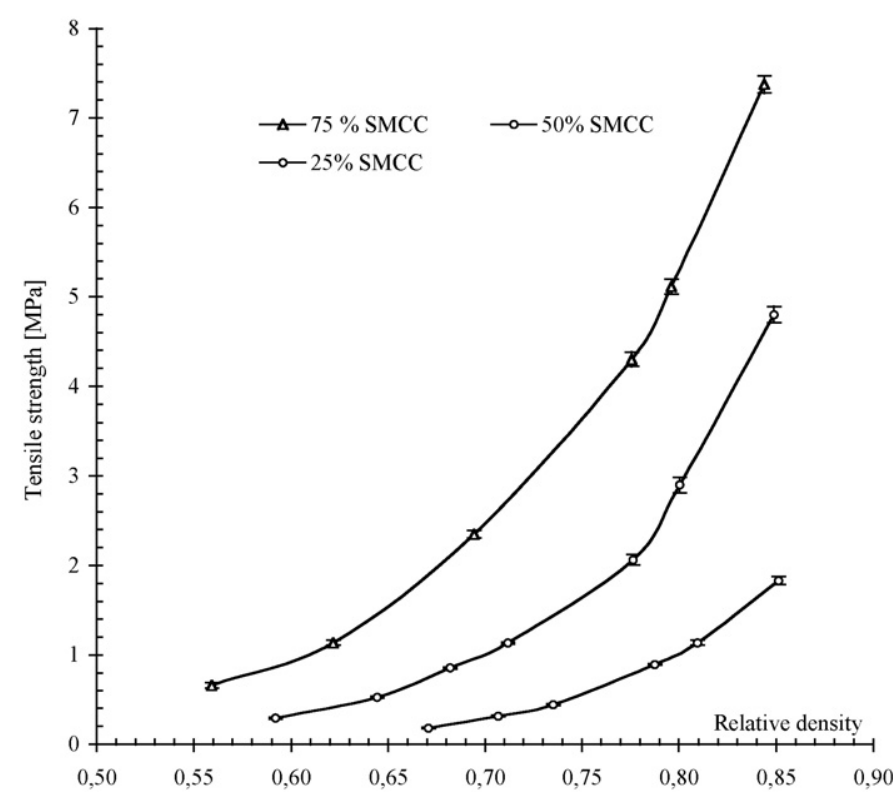

Fig. 3. Tensile strength against relative density: mixture of SMCC and lactose (tablets prepared in a $11.28 \mathrm{~mm}$ die diameter at different pressures.

sistent with results of Wu et al. (2005) and seems to confirm the validity of the linear mixing rule for computing the true density of binary mixtures.

Figs. 3-5 show the "relative density versus tensile strength" graphs change as a function of the mass fraction of cellulose (MCC, SMCC and SMCC-HD) in the mixtures. It is apparent that the cellulose powder reinforces the binary mixture. This confirms that increases in tensile strength are related to the increase of the proportion of the cellulose powder. The corresponding "porosity versus tensile strength" data were used to fit material parameters (bonding capacity constant; tensile strength at zero porosity) of Ryshkewitch-Duckworth model of

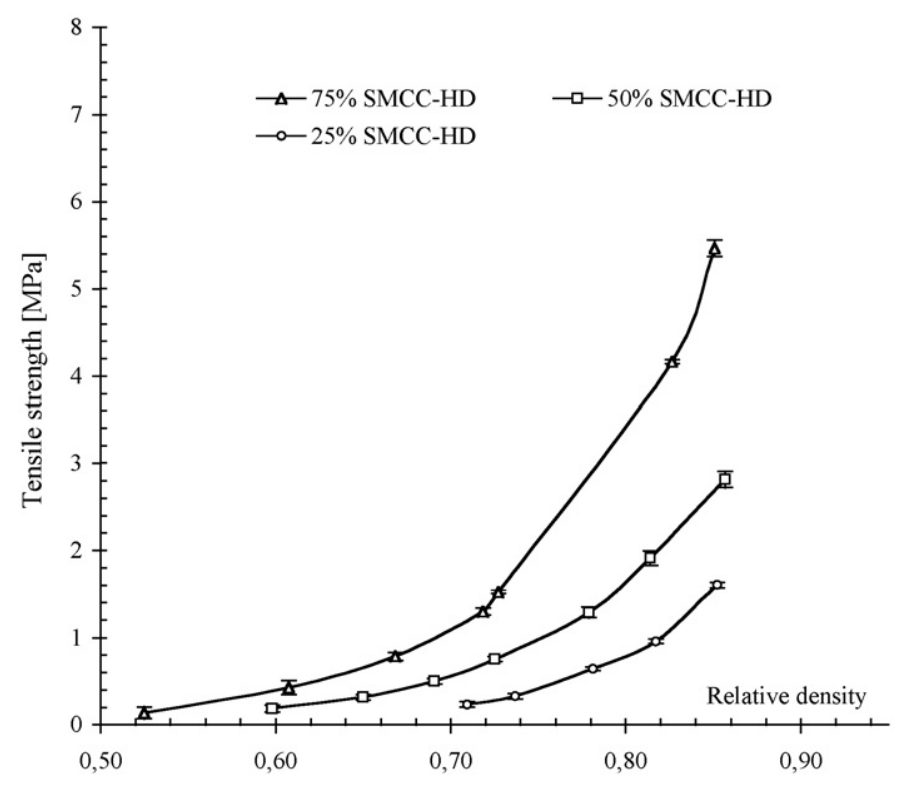

Fig. 4. Effect of SMCC-HD composition in mixtures with lactose on the strength of binary tablets. 


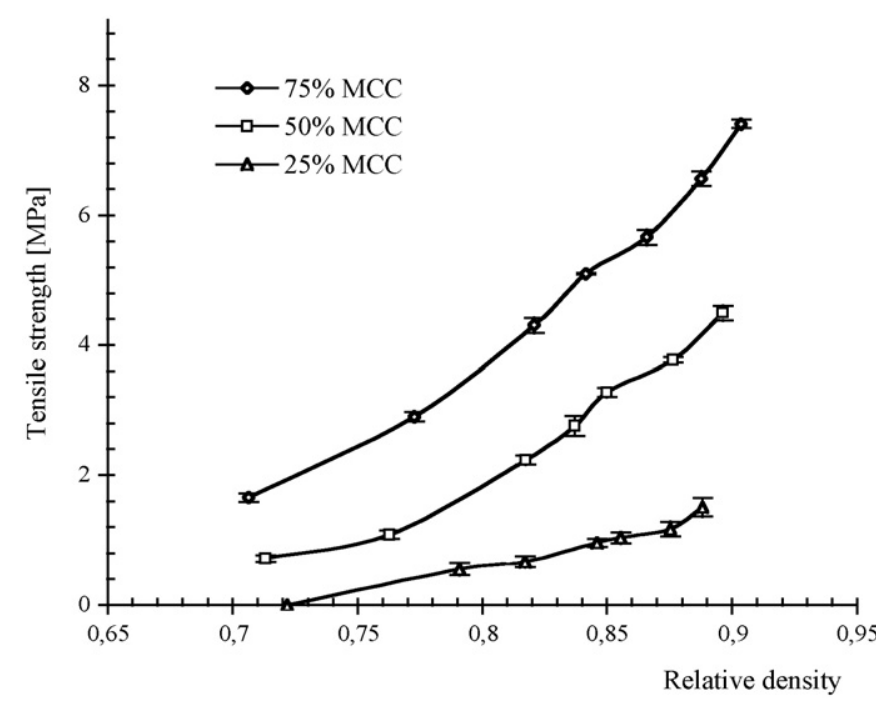

Fig. 5. Strength of binary tablets of MCC/lactose vs. relative density. Effect of the fraction mass of MCC in mixtures.

the studied mixtures. The values of these constants are reported in Table 3. The correlation coefficients $R^{2}\left(R^{2}>0.98\right)$ are also reported and indicate the good fit of data with the model.

The variation of the tensile strength of binary tablets (MCC, SMCC or SMCC-HD) with the mass fraction of the more compactable powder (the compatibility is the ability of powder to produce a tablet with a specific strength) is plotted in Figs. 6 and 7 for pressures of 50 and $150 \mathrm{MPa}$. Changes of porosity as a function of the composition are also reported in the same figures. At a pressure of $50 \mathrm{MPa}$ the porosity increases slightly and linearly with the mass fraction of the cellulose, whereas the strength increases. At higher pressure $(150 \mathrm{MPa})$, the porosity shows a small variation as a function of mixture composition, whereas the tensile strength increases. This is a consequence of the plastic behaviour of the cellulose where at high pressure, the greater is the composition of MCC (respectively, SMCC) the greater the increase in strength with small changes of volume. Measurements of pore diameters by mercury porosimetry may help to understand this increase in strength of tablets with the increase of cellulose composition.

Table 3

Fitted material parameters of Ryshkewitch-Duckworth model from "porosity-tensile strength" measurements of binary mixtures "MCC/lactose", "SMCC-HD/lactose" and "SMCC/lactose"

\begin{tabular}{llrrr}
\hline Binary mixtures & $\begin{array}{l}\text { Mass fraction } \\
\text { of lactose }\end{array}$ & \multicolumn{1}{c}{$\kappa_{\mathrm{m}}$} & \multicolumn{1}{l}{$\sigma_{\infty, \mathrm{m}}$} & \multicolumn{1}{l}{$R^{2}$} \\
& 0.75 & 9.93 & 4.32 & 0.9824 \\
MCC/lactose & 0.5 & 10.45 & 14.33 & 0.9883 \\
& 0.25 & 7.53 & 15.79 & 0.9933 \\
& 0.75 & 13.41 & 11.53 & 0.9982 \\
SMCC-HD/lactose & 0.5 & 10.56 & 13.37 & 0.9979 \\
& 0.25 & 10.47 & 23.28 & 0.9915 \\
SMCC/lactose & 0.75 & 12.76 & 12.85 & 0.9976 \\
& 0.5 & 9.76 & 19.66 & 0.9921 \\
& 0.25 & 8.50 & 25.94 & 0.9926 \\
\hline
\end{tabular}

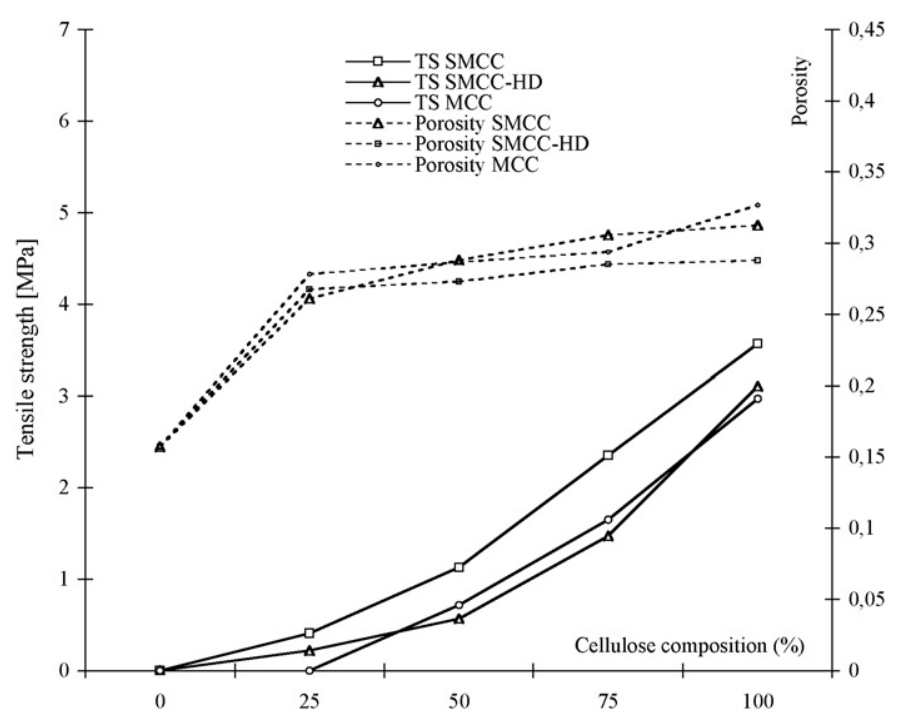

Fig. 6. Tensile strength (TS) and porosity vs. composition of celluloses. Binary mixtures: lactose/SMCC, lactose/SMCC-HD and lactose/MCC (pressure $=50 \mathrm{MPa})$.

\subsection{Predictions of tensile strength for binary mixtures}

The combinations (LL), (PP), (LP) and (PL) of the linear mixing rule and power law predicting $\kappa_{\mathrm{m}}$ and $\sigma_{\infty, \mathrm{m}}$ and hence tensile strength of a binary mixture from Eq. (12), were applied to the powder mixtures studied (SMCC/lactose, SMCC$\mathrm{HD} /$ lactose and MCC/lactose). The determination of $\kappa_{\mathrm{m}}$ and $\sigma_{\infty, \mathrm{m}}$ for each composition requires values of bonding constant and tensile strength at zero porosity of single-components (reported in Table 1) and the volume fraction $\eta$. Then the tensile strength was evaluated from Eq. (12) for the same porosities as measured. In Table 4a (respectively, Tables 5a and 6a) are

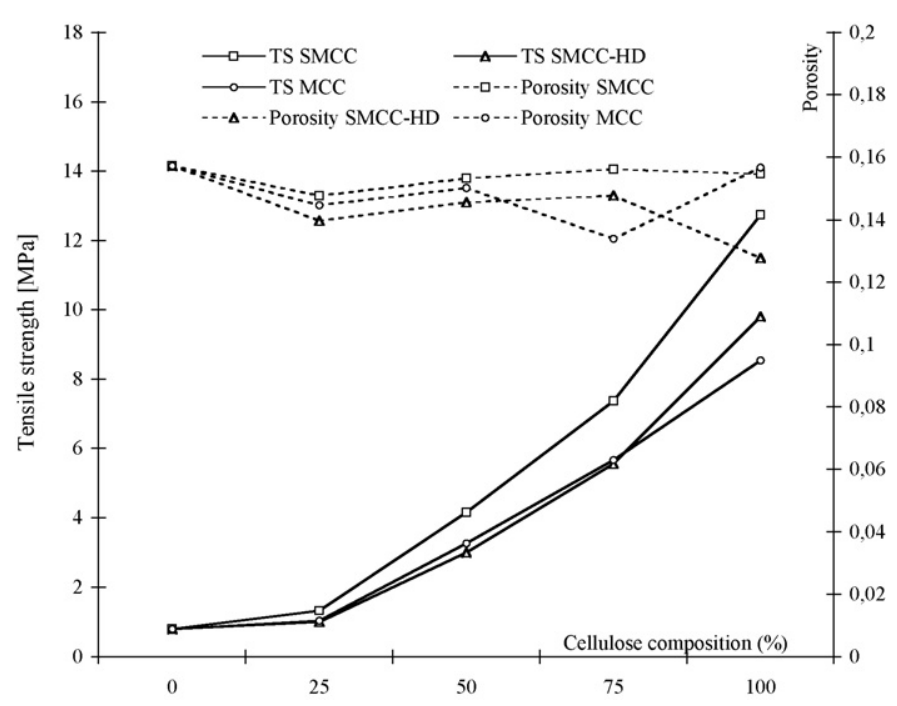

Fig. 7. Correlation between tensile strength (TS) and porosity vs. composition of celluloses. Binary mixtures: lactose/SMCC, lactose/SMCC-HD and $\mathrm{MCC} /$ lactose $($ pressure $=150 \mathrm{MPa})$. 
Table $4 \mathrm{a}$

Predictions of tensile strength for binary mixtures tablets (SMCC/lactose) with Ryshkewitch-Duckworth model according to (LL), (PP), (LP) and (PL) combinations for calculating $\sigma_{\infty, \mathrm{m}}$ and $\kappa_{\mathrm{m}}$ from values of components in Table 1

\begin{tabular}{|c|c|c|c|c|c|c|}
\hline Mass fraction of mixtures & Porosity & $\begin{array}{l}\sigma_{\mathrm{t}}(\mathrm{MPa}), \\
\text { measured }\end{array}$ & $\begin{array}{l}\sigma_{\mathrm{t}}(\mathrm{MPa}) \\
\text { model }(\mathrm{LL})\end{array}$ & $\begin{array}{l}\sigma_{\mathrm{t}}(\mathrm{MPa}) \\
\text { model }(\mathrm{PP})\end{array}$ & $\begin{array}{l}\sigma_{\mathrm{t}}(\mathrm{MPa}) \\
\text { model }(\mathrm{LP})\end{array}$ & $\begin{array}{l}\sigma_{\mathrm{t}}(\mathrm{MPa}), \\
\text { model }(\mathrm{PL})\end{array}$ \\
\hline \multirow{8}{*}{$75 \%$ SMCC $/ 25 \%$ lactose } & 0.53 & 0.24 & 0.10 & 0.15 & 0.17 & 0.09 \\
\hline & 0.44 & 0.66 & 0.26 & 0.37 & 0.41 & 0.23 \\
\hline & 0.38 & 1.14 & 0.50 & 0.68 & 0.77 & 0.46 \\
\hline & 0.34 & 1.61 & 0.80 & 1.04 & 1.17 & 0.74 \\
\hline & 0.30 & 2.24 & 1.25 & 1.54 & 1.74 & 1.14 \\
\hline & 0.22 & 3.84 & 2.70 & 3.11 & 3.50 & 2.47 \\
\hline & 0.20 & 4.72 & 3.53 & 3.97 & 4.47 & 3.24 \\
\hline & 0.14 & 6.95 & 6.64 & 7.03 & 7.92 & 6.08 \\
\hline \multirow{7}{*}{$50 \%$ SMCC/50\% lactose } & 0.41 & 0.29 & 0.08 & 0.13 & 0.15 & 0.07 \\
\hline & 0.36 & 0.53 & 0.17 & 0.25 & 0.29 & 0.15 \\
\hline & 0.32 & 0.85 & 0.29 & 0.40 & 0.46 & 0.25 \\
\hline & 0.29 & 1.14 & 0.45 & 0.59 & 0.68 & 0.39 \\
\hline & 0.22 & 2.06 & 1.08 & 1.32 & 1.51 & 0.95 \\
\hline & 0.20 & 2.46 & 1.58 & 1.85 & 2.11 & 1.38 \\
\hline & 0.15 & 3.73 & 2.99 & 3.26 & 3.73 & 2.61 \\
\hline \multirow{6}{*}{$25 \%$ SMCC $/ 75 \%$ lactose } & 0.33 & 0.18 & 0.07 & 0.09 & 0.10 & 0.06 \\
\hline & 0.29 & 0.32 & 0.13 & 0.16 & 0.18 & 0.11 \\
\hline & 0.26 & 0.44 & 0.20 & 0.25 & 0.28 & 0.18 \\
\hline & 0.21 & 0.89 & 0.50 & 0.57 & 0.64 & 0.44 \\
\hline & 0.19 & 1.14 & 0.72 & 0.80 & 0.91 & 0.64 \\
\hline & 0.15 & 1.83 & 1.48 & 1.56 & 1.76 & 1.31 \\
\hline
\end{tabular}

Table 4b

Mean and dispersion for models LL, PP, LP and PL (SMMC/lactose mixtures)

\begin{tabular}{|c|c|c|c|c|c|}
\hline Mixtures & Porosity range & Mean \pm dispersion $(\mathrm{LL})$ & Mean \pm dispersion $(\mathrm{PP})$ & Mean \pm dispersion $(\mathrm{LP})$ & Mean \pm dispersion (PL) \\
\hline $75 \%$ SMCC $-25 \%$ lactose & $0.14-0.53$ & $0.70 \pm 0.37$ & $0.46 \pm 0.26$ & $0.40 \pm 0.25$ & $0.87 \pm 0.42$ \\
\hline $50 \%$ SMCC $-50 \%$ lactose & $0.15-0.41$ & $0.63 \pm 0.25$ & $0.47 \pm 0.18$ & $0.30 \pm 0.18$ & $0.75 \pm 0.34$ \\
\hline $25 \%$ SMCC $-75 \%$ lactose & $0.15-0.33$ & $0.29 \pm 0.11$ & $0.23 \pm 0.09$ & $0.16 \pm 0.07$ & $0.34 \pm 0.015$ \\
\hline
\end{tabular}

Table 5a

Predictions of tensile strength of binary mixtures tablets (SMCC-HD/lactose) with Ryshkewitch-Duckworth model according to (LL), (PP), (LP) and (PL) combinations for calculating $\sigma_{\infty, \mathrm{m}}$ and $\kappa_{\mathrm{m}}$ from values of components in Table 1

\begin{tabular}{|c|c|c|c|c|c|c|}
\hline Mass fraction of mixtures & Porosity & $\begin{array}{l}\sigma_{\mathrm{t}}(\mathrm{MPa}), \\
\text { measured }\end{array}$ & $\begin{array}{l}\sigma_{\mathrm{t}}(\mathrm{MPa}) \\
\text { model }(\mathrm{LL})\end{array}$ & $\begin{array}{l}\sigma_{\mathrm{t}}(\mathrm{MPa}) \\
\text { model }(\mathrm{PP})\end{array}$ & $\begin{array}{l}\sigma_{\mathrm{t}}(\mathrm{MPa}) \\
\text { model }(\mathrm{LP})\end{array}$ & $\begin{array}{l}\sigma_{\mathrm{t}}(\mathrm{MPa}), \\
\text { model }(\mathrm{PL})\end{array}$ \\
\hline \multirow{6}{*}{$75 \%$ SMCC-HD/25\% lactose } & 0.48 & 0.14 & 0.15 & 0.25 & 0.26 & 0.14 \\
\hline & 0.39 & 0.43 & 0.35 & 0.54 & 0.56 & 0.34 \\
\hline & 0.33 & 0.78 & 0.67 & 0.94 & 0.98 & 0.64 \\
\hline & 0.28 & 1.23 & 1.13 & 1.51 & 1.56 & 1.09 \\
\hline & 0.26 & 1.57 & 1.40 & 1.82 & 1.88 & 1.35 \\
\hline & 0.16 & 4.09 & 4.18 & 4.84 & 5.00 & 4.04 \\
\hline \multirow{7}{*}{$50 \%$ SMCC-HD/50\% lactose } & 0.40 & 0.19 & 0.07 & 0.14 & 0.15 & 0.07 \\
\hline & 0.35 & 0.32 & 0.15 & 0.26 & 0.27 & 0.15 \\
\hline & 0.31 & 0.55 & 0.27 & 0.42 & 0.44 & 0.25 \\
\hline & 0.27 & 0.75 & 0.43 & 0.64 & 0.67 & 0.41 \\
\hline & 0.22 & 1.29 & 0.89 & 1.23 & 1.29 & 0.85 \\
\hline & 0.19 & 1.91 & 1.45 & 1.87 & 1.97 & 1.38 \\
\hline & 0.14 & 2.81 & 2.59 & 3.13 & 3.28 & 2.47 \\
\hline \multirow{5}{*}{$25 \%$ SMCC-HD/75\% lactose } & 0.29 & 0.24 & 0.11 & 0.16 & 0.17 & 0.11 \\
\hline & 0.26 & 0.33 & 0.18 & 0.25 & 0.26 & 0.17 \\
\hline & 0.22 & 0.64 & 0.39 & 0.50 & 0.52 & 0.37 \\
\hline & 0.18 & 0.96 & 0.71 & 0.87 & 0.91 & 0.68 \\
\hline & 0.15 & 1.60 & 1.28 & 1.50 & 1.56 & 1.23 \\
\hline
\end{tabular}


Table $5 b$

Corresponding mean and dispersion values for models LL, PP, LP and PL (SMMC-HD/lactose mixtures)

\begin{tabular}{|c|c|c|c|c|c|}
\hline Mixtures & Porosity range & Mean \pm dispersion $(\mathrm{LL})$ & Mean \pm dispersion $(\mathrm{PP})$ & Mean \pm dispersion $(\mathrm{LP})$ & Mean \pm dispersion $(\mathrm{PL})$ \\
\hline $75 \%$ SMCC-HD/25\% lactose & $0.16-0.48$ & $0.53 \pm 0.97$ & $0.18 \pm 0.22$ & $0.33 \pm 0.27$ & $0.11 \pm 0.07$ \\
\hline $50 \%$ SMCC-HD/50\% lactose & $0.14-0.4$ & $0.28 \pm 0.12$ & $0.11 \pm 0.09$ & $0.11 \pm 0.15$ & $0.32 \pm 0.13$ \\
\hline $25 \%$ SMCC-HD/75\% lactose & $0.15-0.29$ & $0.22 \pm 0.07$ & $0.10 \pm 0.03$ & $0.07 \pm 0.03$ & $0.24 \pm 0.09$ \\
\hline
\end{tabular}

Table 6a

Predictions of tensile strength of binary mixtures tablets (MCC/lactose) with Ryshkewitch-Duckworth model according to (LL), (PP), (LP) and (PL) combinations for calculating $\sigma_{\infty, \mathrm{m}}$ and $\kappa_{\mathrm{m}}$ from values of components in Table 1

\begin{tabular}{|c|c|c|c|c|c|c|}
\hline Mass fraction of mixtures & Porosity & $\begin{array}{l}\sigma_{\mathrm{t}}(\mathrm{MPa}), \\
\text { measured }\end{array}$ & $\begin{array}{l}\sigma_{\mathrm{t}}(\mathrm{MPa}) \\
\text { model }(\mathrm{LL})\end{array}$ & $\begin{array}{l}\sigma_{\mathrm{t}}(\mathrm{MPa}) \\
\text { model }(\mathrm{PP})\end{array}$ & $\begin{array}{l}\sigma_{\mathrm{t}}(\mathrm{MPa}) \\
\text { model }(\mathrm{LP})\end{array}$ & $\begin{array}{l}\sigma_{\mathrm{t}}(\mathrm{MPa}), \\
\text { model }(\mathrm{PL})\end{array}$ \\
\hline \multirow{6}{*}{$75 \% \mathrm{MCC} / 25 \%$ lactose } & 0.29 & 0.14 & 1.14 & 1.71 & 1.75 & 1.12 \\
\hline & 0.23 & 0.43 & 2.16 & 2.95 & 3.01 & 2.12 \\
\hline & 0.18 & 0.78 & 3.42 & 4.35 & 4.44 & 3.35 \\
\hline & 0.16 & 1.23 & 4.18 & 5.15 & 5.25 & 4.09 \\
\hline & 0.13 & 1.57 & 5.28 & 6.28 & 6.41 & 5.17 \\
\hline & 0.11 & 4.09 & 6.50 & 7.49 & 7.65 & 6.37 \\
\hline \multirow{7}{*}{$50 \% \mathrm{MCC} / 50 \%$ lactose } & 0.29 & 0.19 & 0.39 & 0.70 & 0.72 & 0.38 \\
\hline & 0.24 & 0.32 & 0.75 & 1.20 & 1.24 & 0.73 \\
\hline & 0.18 & 0.55 & 1.54 & 2.20 & 2.26 & 1.50 \\
\hline & 0.15 & 0.75 & 2.36 & 3.14 & 3.24 & 2.29 \\
\hline & 0.15 & 1.29 & 2.36 & 3.14 & 3.24 & 2.29 \\
\hline & 0.12 & 1.91 & 3.34 & 4.21 & 4.34 & 3.25 \\
\hline & 0.10 & 2.81 & 4.36 & 5.26 & 5.42 & 4.23 \\
\hline \multirow{5}{*}{$25 \% \mathrm{MCC} / 75 \%$ lactose } & 0.28 & 0.24 & 0.14 & 0.23 & 0.23 & 0.14 \\
\hline & 0.21 & 0.33 & 0.46 & 0.64 & 0.65 & 0.45 \\
\hline & 0.18 & 0.64 & 0.71 & 0.95 & 0.97 & 0.69 \\
\hline & 0.15 & 0.96 & 1.14 & 1.46 & 1.49 & 1.12 \\
\hline & 0.14 & 1.60 & 1.34 & 1.68 & 1.72 & 1.31 \\
\hline
\end{tabular}

Table 6b

Mean and dispersion values

\begin{tabular}{|c|c|c|c|c|c|}
\hline Mixtures & Porosity range & Mean \pm dispersion $(\mathrm{LL})$ & Mean \pm dispersion $(\mathrm{PP})$ & Mean \pm dispersion (LP) & Mean \pm dispersion $(\mathrm{PL})$ \\
\hline $75 \% \mathrm{MCC} / 25 \%$ lactose & $0.11-0.29$ & $2.41 \pm 0.86$ & $3.28 \pm 1.0$ & $3.38 \pm 1.03$ & $2.33 \pm 0.83$ \\
\hline $50 \% \mathrm{MCC} / 50 \%$ lactose & $0.10-0.29$ & $1.04 \pm 0.51$ & $1.72 \pm 0.71$ & $1.80 \pm 0.75$ & $0.98 \pm 0.47$ \\
\hline $25 \% \mathrm{MCC} / 75 \%$ lactose & $0.14-0.28$ & $0.15 \pm 0.07$ & $0.24 \pm 0.18$ & $0.26 \pm 0.18$ & $0.14 \pm 0.08$ \\
\hline
\end{tabular}

Comparison between models LL, PP, LP and PL (MMC/lactose mixtures).

given predictions of tensile strength of mixtures SMCC/lactose (respectively, SMCC-HD/lactose, MCC/lactose). The measured tensile strength is also listed.

In order to compare the predictions of the different combinations with the measurements for all compositions and over the range of porosities, the average and standard deviation (Eqs. (13) and (14) for each composition and for each range of porosity were used. Results of the evaluation are presented in Table $4 \mathrm{~b}$ (respectively, Tables $5 \mathrm{~b}$ and $6 \mathrm{~b}$ ) for SMCC/lactose mixtures (respectively, SMCC-HD/lactose and MCC/lactose). It can be seen from results for mixtures SMCC/lactose and SMCC-HD/lactose, that combination (LP) gives the best predictions, whereas combination (PL) was the best for mixtures MCC/lactose. However, this result should not be systematically generalised for others powders. The best combination depends on powders, the number of measurements of single-components, the precision on the measurements ....

\section{Conclusion}

Experiments have been performed to determine the tensile strength of tablets compressed from single powders of lactose, microcrystalline cellulose (MCC) and two silicified microcrystalline cellulose having different levels of compressibility (SMCC and SMCC-HD). Binary tablets have also been made from mixtures of lactose and these components and their tensile strength determined as a function of mixture composition. It is found that the tensile strength increases with the relative density, for single and binary powder mixtures. For binary tablets, it is shown that the tensile strength increases with the cellulose composition while the porosity undergoes slight changes. As the porosity is the primary factor influencing tensile strength, estimation of changes of median pore diameter (mercury porosimetry) as a function of the composition of cellulose may be a more pertinent analysis. 
Predictions of the tensile strength of binary tablets from the properties of single-components have been analysed with Ryshkewitch-Duckworth model by assuming either a linear mixing rule or a power mixing law rule for the determination of material parameters. The different combinations (four) were analysed and compared with measurements by using statistical criteria based on the mean values and the standard deviation over the range of porosities studied. Good predictions were obtained with the linear mixing rule combined with the power law. However, as the predictions of these models depend on the powders and the range of porosity rmeasurements, the conclusions are only valid for the powders used in this study and should not be systematically generalised to other powders.

\section{Acknowledgement}

We would like to thank Mr. Laurent Ouvrard from the company J. Rettenmaier \& Shöne (France) for the given lots of powders Prosolv ${ }^{\circledR} 90$ and Prosolv ${ }^{\circledR} 90$ HD.

\section{References}

Busignies, V., Leclerc, B., Porion, P., Evesque, P., Couarraze, G., Tchoreloff, P., 2006a. Investigation and modelling approach of the mechanical properties of compacts made with binary mixtures of pharmaceutical excipients. Eur. J. Pharm. Biopharm. 64, 51-65.

Busignies, V., Leclerc, B., Porion, P., Evesque, P., Couarraze, G., Tchoreloff, P., 2006b. Compaction behaviour and new predictive approach to the compressibility of binary mixtures of pharmaceutical excipients. Eur. J. Pharm. Biopharm. 64, 66-74.

Chan, S.Y., Pilpel, N., Cheng, D.C.-H., 1983. The tensile strengths of single powders and binary mixtures. Powder Technol. 34, 173-189.
Duckworth, W., 1953. Discussion of Ryshkewitch paper. J. Am. Ceram. Soc. $36,68$.

Fell, J.T., Newton, J.M., 1970. Determination of tablet strength by the diametrical compression test. J. Pharm. Sci. 59, 688-691.

Hutin, S., Accart, P., Oulahna, D., Dodds, J.A., 2003. Formulation of solid products: two component tablets with a disintegrating agent. Polym. Int. 52, 581-585.

Leuenberger, H., 1985. Compression of binary powder mixtures and solubility parameters of solids. Int. J. Pharm. 27, 127-138.

Kuentz, M., Leuenberger, H., 2000. A new theoretical approach to tablet strength of binary mixture consisting of a well and poorly compactable substance. Eur. J. Pharm. Biopharm. 49, 151-159.

Ramirez, N., Melgoza, L.M., Kuentz, M., Sandoval, H., Caraballo, I., 2004 Comparison of different mathematical models for tensile strength-relative density profiles of binary tablets. Eur. J. Pharm. Sci. 22, 19-23.

Riepma, K.A., Lerk, C.F., De Boer, A.H., Bolhuis, G.K., Kussendrager, K.D. 1990. Consolidation and compaction of powder mixtures. I. Binary mixtures of same particle size fractions of different types of crystalline lactose. Int. J. Pharm. 66, 47-52.

Ryshkewitch, E., 1953. Compression strength of porous sintered alumina and zirconia. J. Am. Ceram. Soc. 36, 65-68.

Sheikh-Salem, M., Fell, J.T., 1981. Compaction characteristics of mixtures of materials with dissimilar compaction mechanisms. Int. J. Pharm. Tech. Manuf. 2, 19-22.

Sherwood, B.E., Becker, J.W., October 1998. A new class of high functionality excipients: silicified microcrystalline cellulose. Pharm. Technol. 10, 78-83.

Van Veen, B., Van der Voort Maarschalk, K., Bolhuis, G.K., Frijlink, H.W., 2004. Predicting mechanical properties of compacts containing two components. Powder Technol. 139, 156-164.

Vromans, H., Lerk, C.F., 1988. Densification properties and compactability of mixtures of pharmaceutical excipients with and without magnesium stearate. Int. J. Pharm. 46, 183-192.

Wu, C.-Y., Best, S.M., Bentham, A.C., Hancock, B.C., Bonfield, W., 2005. A simple predictive model for the tensile strength of binary tablets. Eur. J. Pharm. Sci. 25, 331-336. 